\title{
MINA WISATA SEBAGAI ALTERNATIF PENGEMBANGAN WISATA BAHARI DI KAWASAN PESISIR BULELENG, BALI UTARA
}

\author{
Gede Ari Yudasmara') \\ 1)Jurusan Budidaya Kelautan, Fakultas Matematika dan IImu Pengetahuan Alam, Universitas Pendidikan Ganesha \\ Diterima tanggal: 7 Januari 2016; Diterima setelah perbaikan: 23 Februari 2016; Disetujui terbit tanggal 2 Maret 2016
}

\begin{abstract}
ABSTRAK
Kawasan pesisir Kabupaten Buleleng saat ini telah dimanfaatkan dengan berbagai kegiatan kepariwisataan, akan tetapi kegiatan tersebut masih belum memberikan manfaat yang optimal bagi masyarakat dan memiliki kecenderungan mengalami kejenuhan. Untuk itu, diperlukan suatu pengembangan wisata alternatif yang sesuai dengan kondisi dan potensi sumber daya alam yang ada serta saling bersinergi dengan aktivitas wisata lainnya, seperti contohnya pengembangan mina wisata. Penelitian ini bertujuan untuk mengkaji dan menganalisis kondisi dan potensi sumber daya alam pesisir dan laut, tingkat kesesuaian kawasan pesisir Buleleng dalam menunjang pengembangan mina wisata dan menghasilkan model aktivitas mina wisata di kawasan pesisir Buleleng yang terpadu dan berkelanjutan. Penelitian ini menggunakan pendekatan kesesuaian kawasan dengan rancangan penelitiannya berupa survei lapangan. Hasil penelitian menunjukkan bahwa pesisir Kabupaten Buleleng apabila dilihat dari kondisi dan potensi sumber daya alamnya masih mampu untuk mendukung aktivitas mina wisata dengan tingkat kesesuaian kawasan berdasarkan indeks kesesuaian wisata, yaitu pesisir Buleleng timur terkategori cukup sesuai $(76,92)$, pesisir Buleleng tengah terkategori cukup sesuai $(61,53)$ dan pesisir Buleleng barat terkategori sangat sesuai $(87,17)$. Rencana model mina wisata yang dapat dikembangkan antara lain pesisir Buleleng timur adalah mina wisata budi daya laut (ikan hias dan karang) dan mina wisata perikanan tangkap (mancing dan spearfishing adventures), pesisir Buleleng tengah adalah mina wisata budi daya laut (rumput laut) dan mina wisata perikanan tangkap (mancing dan spearfishing adventures), dan pesisir Buleleng barat adalah mina wisata budi daya laut (rumput laut, Bandeng, Kerapu, Mutiara, ikan hias dan karang) dan mina wisata perikanan tangkap (mancing dan spearfishing adventures).
\end{abstract}

Kata kunci: mina wisata, wisata bahari, kawasan pesisir Buleleng, Bali utara

\section{ABSTRACT}

Buleleng Regency coastal area has been used for various tourism activities, however, the activities have not given an optimum benefit for the community and tend to experience saturation. This study was aimed to investigating and analyzing the condition and potentiality of the coastal area and the sea, the degree of fit of Buleleng coastal area in supporting the development of fisheries tourism and at producing a model of the coastal area tourism activities that are integrated and sustainable. This study used the approach of area suitability with field survey design. The results show that Buleleng Regency coastal area, viewed from the point of the condition and the potentiality of the natural resources still has the capacity to support fisheries tourism. The model plannings of fisheries tourisms that can be developed, among others, are: the East Buleleng coastal area is suitable for marine culture fisheries tourism (ornamental fish and coral) and fished fisheries tourism (fishing and spearfishing adventures); the central Buleleng coastal area for marine culture fisheries tourism (seaweed) and fished fisheries tourism (fishing and spearfishing adventures), and the West Buleleng coastal area for marine culture fisheries tourism (seaweed, milk fish, grouper, pearl, ornamental fish and coral) and fished fisheries tourism (fishing and spearfishing adventures).

\section{Keywords: fisheries tourism, marine tourism, Buleleng coastal area, North Bali}

\section{PENDAHULUAN}

Kabupaten Buleleng yang secara geografis terletak di bagian utara Pulau Bali memiliki potensi kelautan cukup tinggi. Hal ini terkait dengan panjang pantai hingga mencapai $157,05 \mathrm{~km}$ (BPS, 2013). Kondisi ini tentunya memberikan peluang bagi berbagai usaha pemanfaatan termasuk didalamnya pengembangan dan peningkatan sektorkepariwisataan. Kendatipun kabupaten ini telah mengembangkan kegiatan kepariwisataan, terutama wisata bahari, namun kegiatan tersebut masih belum memberikan manfaat yang optimal bagi masyarakat dan memiliki kecenderungan mengalami kejenuhan. Di sisi lain kualitas sumber daya dan lingkungan di beberapa tempat wisata juga mengalami penurunan. Penurunan atau kerusakan kondisi ekosistem terumbu karang seperti yang terjadi di kawasan Pulau Menjangan telah mencapai hingga $46 \%$ di tahun 2010 (Yudasmara, 2010). Menurut (Tratalos \& Austin, 2001), (Zakai \&
Chadwick, 2002) dan (Davenport \& Davenport, 2006) menyebutkan bahwa penurunan kondisi terumbu karang dapat disebabkan oleh intensitas aktivitas bawah laut yang terlalu tinggi, sehingga diperlukan pendekatan pengelolaan yang mampu melestarikan kualitas ekologi dan estetika tempat menyelam tersebut.

Hal ini menggambarkan bahwa aktivitas wisata bahari di Kabupaten Buleleng perlu dibenahi dan dikembangkan aktivitas wisata alternatif lainnya yang sesuai dengan kondisi dan potensi sumber daya alam yang ada serta saling bersinergi dengan aktivitas wisata yang sudah lebih dahulu ada, seperti contohnya pengembangan mina wisata. Konsep mina wisata adalah pemanfaatan kawasan wisata dengan pengembangan produksi perikanan untuk mencapai ketertarikan masyarakat pengguna akan pengembangan perikanan pada kawasan wisata tersebut (Darmawan \& Miftahul, 2012). Dengan kata 
lain, Mina wisata adalah pengembangan kegiatan perekonomian masyarakat dan wilayah yang berbasis pada pemanfaatan potensi sumber daya kelautan, perikanan dan pariwisata secara terintegrasi pada suatu wilayah tertentu (Kasnir, 2011). (Erlend et al., 2011) menyebutkan bahwa pengembangan wisata perikanan atau mina wisata dapat meningkatkan keuntungan ekonomi dalam skala lokal sehingga dapat menjadi alternatif bentuk wisata di kawasan pesisir dan laut.

Beberapa hasil kajian tentang mina wisata (Volstad et al., 2011), (Kasnir, 2011), (Strehlow et al., 2012) dan (Ferter et al., 2013) disebutkan bahwa diperlukannya beberapa skenario pengelolaan di dalam pengembangan wisata perikanan berdasarkan daya dukung dan potensi sumber daya alam yang tersedia agar tercapainya konsep pengelolaan yang berkelanjutan. Berdasarkan hal tersebut maka permasalahan pengelolaan wisata bahari di Kabupaten Buleleng perlu dijawab dengan dihasilkannya suatu model atau skenario pengembangan dan pengelolaan mina wisata yang terpadu dan berkelanjutan dengan harapan model ini mampu meningkatkan daya saing masyarakat Buleleng dan menjadi wisata alternatif dari aktivitas wisata yang telah lebih dahulu berkembang. Bertolak dari hal tersebut maka penelitian ini dilakukan melalui survei lapangan dengan menggunakan pendekatan kesesuaian kawasan. Penelitian ini bertujuan untuk mengkaji dan menganalisis kondisi potensi sumber daya alam pesisir dan tingkat kesesuaian kawasan pesisir Buleleng dalam menunjang aktivitas mina wisata; menemukan dan menghasilkan model pengembangan dan pengelolaan mina wisata yang tepat secara ekologi, ekonomi dan sosial dalam menjamin keberlangsungan sumber daya alam dan kehidupan sosial ekonomi masyarakat setempat.

\section{METODE PENELITIAN}

\section{Waktu dan Tempat Penelitian}

Penelitian ini dilaksanakan dari April sampai Agustus 2014 dengan lokasi penelitian sepanjang pesisir Kabupaten Buleleng-Bali Utara yang terbagi dalam 3 (tiga) stasiun pengamatan, yaitu: pesisir Buleleng Timur, Tengah, dan Barat (Gambar 1). Secara spesifik pengambilan sampel di ketiga stasiun tersebut mempertimbangkan kawasan yang sudah ada aktivitas wisatanya, dengan maksud agar mudah nantinya diperkenalkan kepada para wisatawan yang datang berkunjung ke kawasan tersebut.

\section{Pengambilan Data}

Penelitian ini menggunakan rancangan berupa survei lapangan. Data primer diperoleh melalui melalui

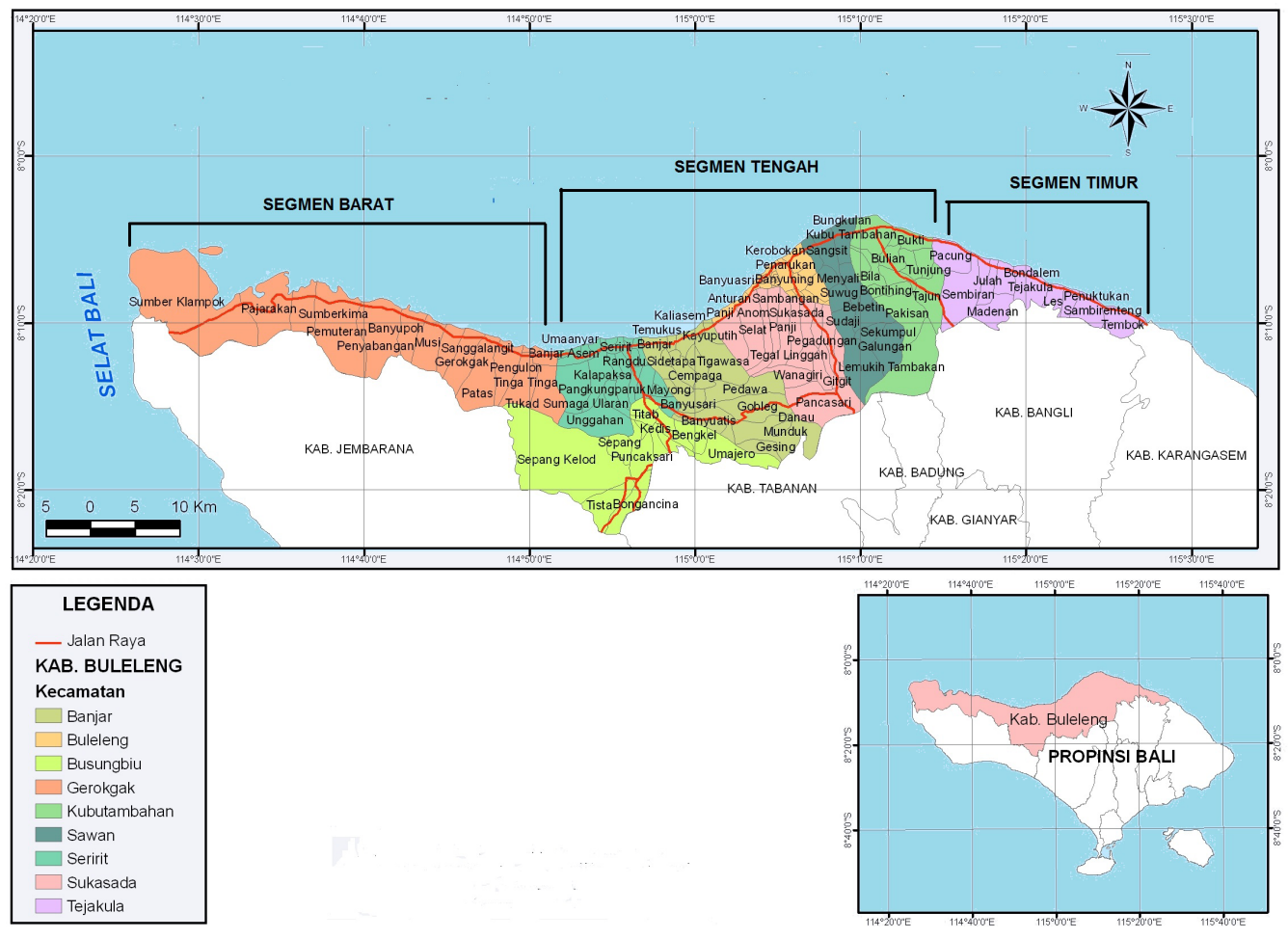

Gambar 1. Lokasi penelitian. 
observasi (pengamatan lapangan) dan wawancara langsung, sedangkan data sekunder diperoleh melalui kajian laporan hasil penelitian, publikasi ilmiah, Dinas Kelautan dan Perikanan, Dinas Pariwisata, dan Bappeda Buleleng. Untuk pengamatan kondisi karang menggunakan metode Manta Tow dan Line Intercept Transect (LIT) mengikuti (English et al., 1994), pengamatan ikan menggunakan Underwater fish Visual Census (UVC), pengamatan kualitas air menggunakan alat water quality checker (merk Horiba), dan pengamatan sosial ekonomi masyarakat melalui wawancara langsung dan penyebaran kuesioner. Jenis dan sumber data yang diperlukan dalam penelitian dapat dilihat dalam Tabel 1.

\section{Analisis Data}

Data yang diperoleh, dianalisis secara deskriptif kualitatif dan kuantitatif tanpa menggunakan analisis statistika. Untuk penutupan karang, dihitung dengan rumus tutupan karang hidup menurut (English et. al.1994), yaitu :

$$
\text { Penutupan karang }=\frac{\text { Panjang kategori life form ke-i }}{\text { Total panjang transek }} \times 100 \%
$$

(Bachtiar, 2001) menyatakan bahwa persentase penutupan terumbu karang dapat dibagi menjadi lima kategori, yaitu : sangat jelek : 0 - $10 \%$, jelek : 11 - 30 $\%$, sedang : 31 - $50 \%$, baik : 51 - $75 \%$ dan sangat baik: $76-100 \%$. Untuk menganalisis kesesuaian lahan ini mengacu pada (Hutabarat et al., 2009), adalah sebagai berikut:

$$
\mathrm{IKW}=\left[\Sigma \frac{\mathrm{Ni}}{\mathrm{N} \text { maksimum }}\right] \times 100
$$

$$
\begin{aligned}
& \text { dimana; } \\
& \mathrm{IKW} \quad \text { = indeks kesesuaian wisata } \\
& \mathrm{Ni} \quad=\text { nilai parameter ke-i (bobot } \mathrm{x} \text { skor) } \\
& \mathrm{Nmaks}=\text { nilai maksimum }
\end{aligned}
$$

Nilai indeks kesesuaian wisata dapat diperoleh berdasarkan matriks kesesuaian dalam Tabel 2 .

Adapun alur penelitian yang dilakukan dapat dijelaskan melalui Gambar 2.

\section{HASIL DAN PEMBAHASAN}

\section{Kondisi dan Potensi Sumber Daya Kawasan Pesisir Buleleng}

\section{Ekosistem Terumbu Karang}

Terumbu karang sebagai salah satu sumber daya alam di kawasan pesisir Buleleng memiliki gugusan karang yang sangat khas. Berdasarkan hasil pengamatan pada 3 stasiun pengamatan (pesisir Buleleng timur, pesisir Buleleng tengah dan pesisir Buleleng barat), memiliki kontur karang yang beranekaragam dari kontur yang datar sampai ke

Tabel 1.

Jenis dan Sumber Data yang Diperlukan

\begin{tabular}{llll}
\hline No Parameter Jenis Data & Sumber Data & $\begin{array}{l}\text { Metode } \\
\text { Pengumpulan }\end{array}$ & Keterangan \\
\hline
\end{tabular}

tutupan karang, jenis life form, lebar Primer

1 Terumbu karang hamparan datar karang, dan kedalaman terumbu karang dan Sekunder

sampling dengan manta tow, line intercept transect keterwakilan komunitas (English et al., 1994) persyaratan karang dan LIT
Manta tow untuk pemilihan lokasi survei agar memenuhi digunakan agar akurasi data dapat diperoleh dengan baik.

underwater fish visual census

Umum digunakan (English et al., 1994), dan foto bawah laut. dan mudah pengaplikasiannya
2 Ikan hias jenis ikan Primer kecepatan arus, kedalaman, suhu, 3
Kualitas perairan salinitas, DO, turbiditas, Primer $\mathrm{NH}_{3}$, dan $\mathrm{pH}$ sampling dengan bantuan Diperlukan untuk alat water quality checker, melengkapi floater current meter, persyaratan baku mutu tide gaugh. air untuk mina wisata 
J. Segara Vol. 12 No. 1 April 2016: 31-43

Tabel 2. Matriks Kesesuaian Lahan

\begin{tabular}{|c|c|c|c|c|}
\hline No & Parameter & Bobot & Standar Parameter & Skor \\
\hline 1 & Tutupan karang hidup (\%) & 3 & $\begin{array}{l}>75 \\
>50-75 \\
25-50 \\
<25\end{array}$ & $\begin{array}{l}3 \\
2 \\
1 \\
0\end{array}$ \\
\hline 2 & Kecerahan perairan (\%) & 3 & $\begin{array}{l}100 \\
70-<100 \\
20-<70 \\
<20\end{array}$ & $\begin{array}{l}3 \\
2 \\
1 \\
0\end{array}$ \\
\hline 3 & Jumlah jenis life form & 2 & $\begin{array}{l}>12 \\
<7-12 \\
4-7 \\
<4\end{array}$ & $\begin{array}{l}3 \\
2 \\
1 \\
0\end{array}$ \\
\hline 4 & Jumlah jenis ikan karang & 2 & $\begin{array}{l}>100 \\
50-100 \\
20-<50 \\
<20\end{array}$ & $\begin{array}{l}3 \\
2 \\
1 \\
0\end{array}$ \\
\hline 5 & $\begin{array}{l}\text { Kedalaman terumbu } \\
\text { karang }(\mathrm{m})\end{array}$ & 2 & $\begin{array}{l}6-15 \\
>15-20 \text { atau } 3-5 \\
>20-30 \\
>30 \text { atau }<3\end{array}$ & $\begin{array}{l}3 \\
2 \\
1 \\
0\end{array}$ \\
\hline 6 & Kecepatan arus (cm/det) & 1 & $\begin{array}{l}0-15 \\
>15-30 \\
>30-50 \\
>50\end{array}$ & $\begin{array}{l}3 \\
2 \\
1 \\
0\end{array}$ \\
\hline
\end{tabular}

Sumber: (Davis \& Tisdell, 1995); (Davis \& Tisdell, 1996); (deVantier \& Turak, 2004); (DKP, 2003); (Hutabarat et al., 2009); (Simon et al., 2004).

Keterangan:

Nilai maksimum $=39$

S1 = Sangat sesuai, dengan nilai IKW $80-100$

S3 = Sesuai bersyarat, dengan nilai IKW $45-<60$

S2 = Cukup sesuai, dengan nilai IKW $60-<80$ S4 = Tidak sesuai, dengan nilai IKW $<45$

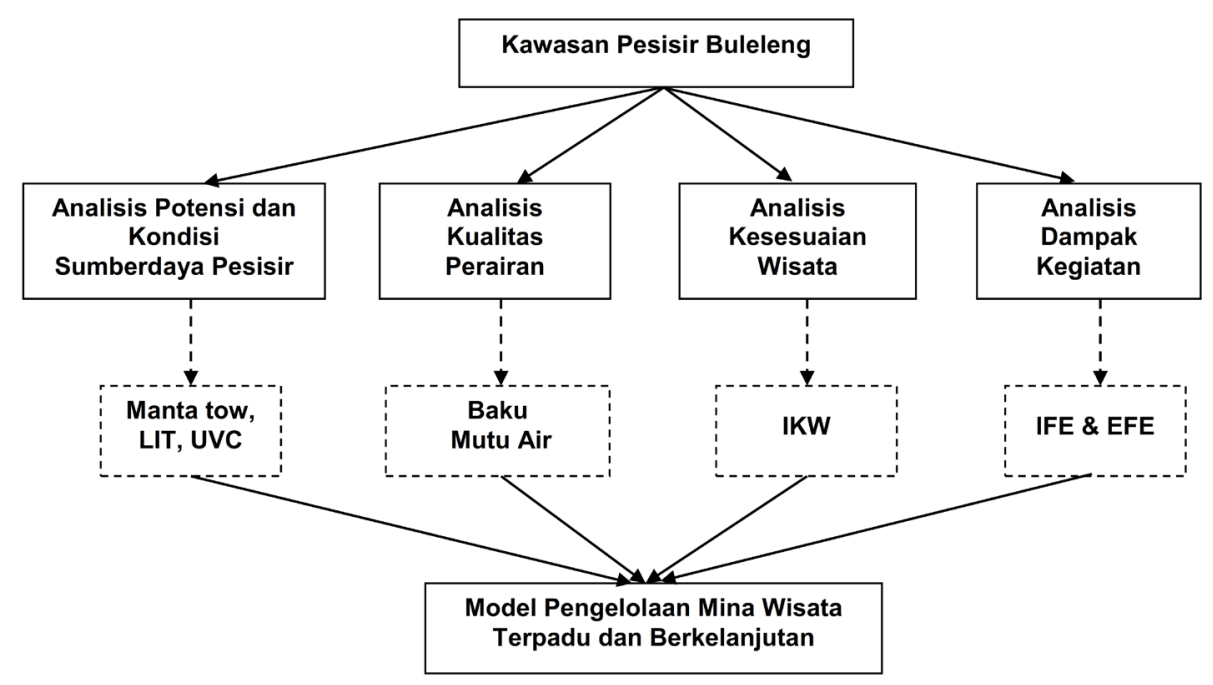

Gambar 2. Alur Penelitian. 
kontur yang tiba-tiba berubah drastis menjadi terjal atau dalam istilah selam disebut "drop off".

Pesisir Buleleng secara keseluruhan hampir merata dikelilingi oleh terumbu karang dari jenis karang tepi. Gambaran persentase tutupan karang di pesisir Buleleng disajikan pada Gambar 3.

Lokasi titik pengamatan pertama berada di pesisir Buleleng bagian timur, yaitu sekitar kecamatan Tejakula pada kedalaman 3 meter dan 10 meter, terdapat hamparan pasir hitam yang luas. Hasil yang didapatkan dengan menggunakan metode LIT, bahwa persentase tutupan karang hidup pada kedalaman 3 meter sebesar 49,35\% jenis Acropora, non Acropora $36,68 \%$, biota lain $28,73 \%$, dead coral $30,15 \%$ dan abiotik $27,60 \%$. Untuk persentase tutupan karang hidup pada kedalaman 10 meter sebesar $16,45 \%$ untuk jenis Acropora, non Acropora sebesar 12,23\%, biota lain 9,58 \%, dead coral 10,05\% dan abiotik 9,20 $\%$.

Jenis Acropora yang ditemukan didominasi oleh Acropora branching, Acropora digitate, dan Acropora tabulate sedangkan non Acropora didominasi oleh Coral foliose, Coral branching, dan Coral massive. Selain itu, dijumpai pula biota lainnya seperti soft coral dan zooxanthid serta karang mati. Komponen abiotik terdiri dari pasir dan rubble (pecahan karang).

Pada stasiun pengamatan I ini profil rataan terumbu dengan kedalaman kurang dari 3 meter banyak diisi oleh hamparan pasir dan karang mati, namun semakin jauh dari pantai semakin banyak karang yang hidup dengan kedalaman lebih dari 3 meter atau berada pada tubir karang. Begitu pula pada kedalaman 10 meter banyak ditemukan patahan-patahan karang, kondisi ini diakibatkan sebelumnya telah terkena hama Acanthaster plancii dan terjadi bleaching. Kondisi ini juga diakibatkan oleh pelemparan/penambatan jangkar dan aktivitas pariwisata yang tidak bersahabat.

Penyelaman dan snorkling yang ceroboh berpotensi dalam memindahkan patahan karang maupun menambah terjadinya patahan karang tersebut. Morfologi tubir dengan derajat kemiringan yang cukup tinggi, menyebabkan jatuhnya patahan karang ke kedalaman di bawahnya, sehingga

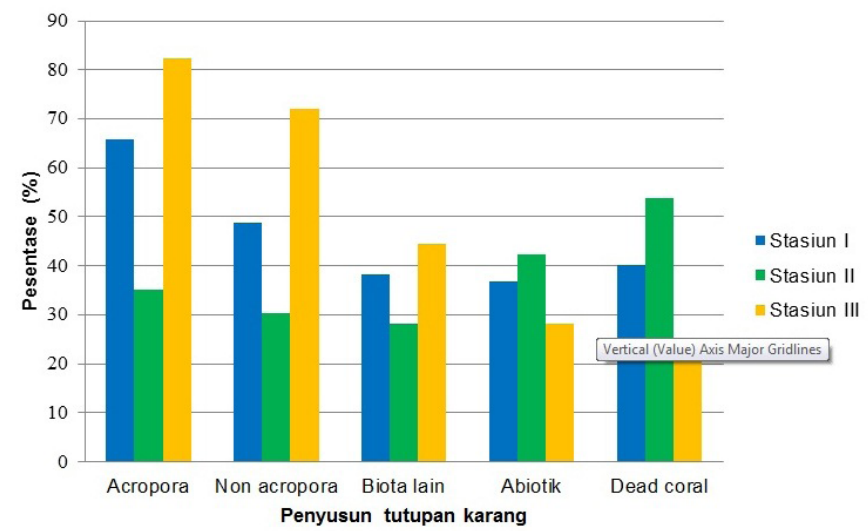

(a)

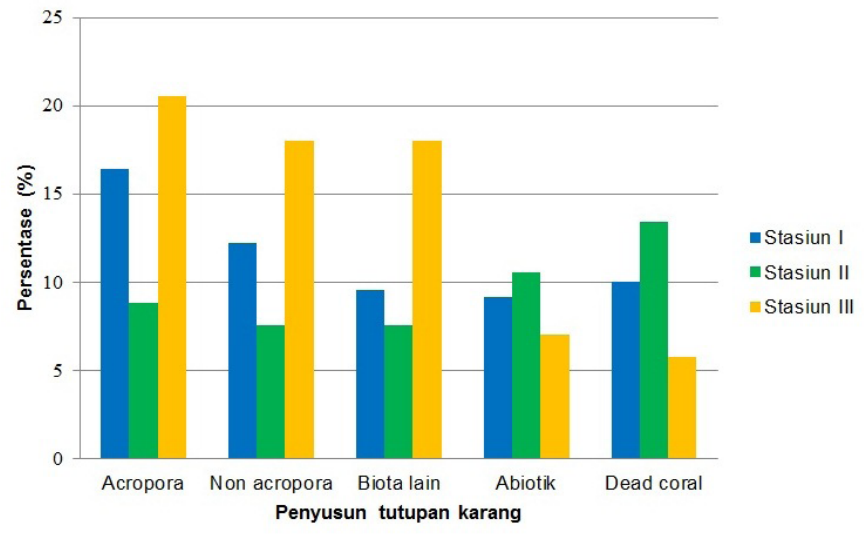

Gambar 3. Presentase Tutupan Karang pada Kedalaman (a) 3 meter dan (b) 10 meter. 
berpotensi menimbulkan kerusakan fisik berantai. Secara umum dapat dikatakan bahwa tutupan karang hidup di stasiun I memiliki kondisi sedang, yaitu sebesar $57,35 \%$.

Stasiun kedua berada di pesisir Buleleng bagian tengah, yaitu berada didekat pemukiman penduduk. Transek diambil pada kedalaman 3 meter dan 10 meter. Persentase tutupan karang hidup pada kedalaman 3 meter adalah sebesar 26,44 \% dari jenis Acropora dan non Acropora sebesar 22,80 \%. Selain itu, ditemukan juga biota lain seperti soft coral dengan persentase tutupan sebesar 21,15\% serta komponen abiotik yang sedikit berupa substrat pasir dan rubble sebesar 31,80 $\%$.

Pada lokasi ini karang mati yang ditemukan berupa bongkahan karang mati dari jenis massive dengan persentase sebesar 40,31 \%. Persentase tutupan karang pada kedalaman sekitar 10 meter adalah sebesar 8,81\% yang didominasi oleh jenis Acropora dan jenis non Acropora hanya 7,60 \%. Pada lokasi ini juga dijumpai juga biota lain seperti soft coral dengan persentase tutupan sebesar 7,05 \%, komponen abiotik yang sedikit berupa substrat pasir dan rubble sebesar 10,60 \% serta persentase tutupan karang mati sebesar $13,44 \%$.

Secara keseluruhan kondisi terumbu karang di stasiun II ini tergolong dalam kategori cukup, yaitu $32,83 \%$ dari kedua kedalaman yang diteliti. Kondisi ini dapat disebabkan karena pada stasiun II banyak terdapat pemukiman penduduk, hotel, gedung-gedung, dan beberapa muara air sungai. Kondisi inilah yang mengakibatkan pada stasiun II ini tutupan karang hidupnya rendah. Terumbu karang akan sulit hidup dan berkembang apabila di lingkungan perairannya tidak mendukung untuk hidupnya, banyaknya muara sungai dan belum lagi banyaknya aktivitas masyarakat di lingkungan pesisir, sehingga memberikan tekanan yang berat bagi karang untuk hidup dan bertahan.

Stasiun ketiga berada di pesisir Buleleng bagian barat, yaitu berada di kecamatan Gerokgak sampai ke kawasan Pesisir Buleleng. Semakin ke arah barat hamparan pasirnya akan semakin berubah dari hitam menjadi putih begitu juga dengan vegetasi pohonnya akan lebih banyak menemukan vegetasi mangrove daripada vegetasi pohon lainnya, seperti kelapa, waru, dan pandan.

Pengukuran transek pada kedalaman 3 meter didapatkan persentase tutupan karang hidup sebesar $61,69 \%$ dengan jenis karang berupa Acropora dan $54,01 \%$ berupa non Acropora. Persentase tutupan untuk biota lain sebesar 33,35 \%, sedangkan komponen abiotik yang terdiri dari substrat pasir dan rubble sebesar 21,12 \% serta persentase tutupan karang mati sebesar 17,34 \%. Untuk pengukuran transek pada kedalaman 10 meter didapatkan hasil berupa Acropora 20,56 \% dan non Acropora 18,00 \%, sedangkan $11,12 \%$ adalah biota lain seperti soft coral. Komponen lain seperti substrat pasir dan rubble sekitar $7,04 \%$ dan tutupan karang mati sebesar 5,78 \%.

Kondisi terumbu karang di stasiun ini tergolong dalam kategori baik yaitu 77,13 \%. Kondisi lingkungan di lokasi ini memiliki gelombang dan arus yang cukup kuat, sehingga perlu perhatian yang lebih. Pengaruh arus tersebut, maka terdapat beberapa hal yang spesifik, seperti banyaknya karang lunak, gorgonian, sponge dan non Acropora (coral foliose, coral massive, coral Submassive, dan coral mushrom) pada rataan terumbu, tubir, dan dinding serta profil dindingnya yang hampir tegak lurus. Menurut (Dexter et al., 2014) dan (Stone et al., 2015) menyatakan bahwa arus perairan yang kuat akan membentuk corak habitat yang cukup beragam, sehingga keanekaragaman bentuk karang menjadi semakin tinggi.

Secara keseluruhan persentase tutupan karang hidup di pesisir Buleleng sebesar $55.77 \%$ atau dalam kategori baik. Menurut kriteria dari (Hutabarat et al., 2009), untuk aktivitas wisata bahari diperlukan syarat kondisi tutupan karang minimal sebesar 25 $\%$ sampai lebih dari $75 \%$. Hasil perhitungan di atas menunjukkan bahwa semua titik stasiun pengamatan dapat dimanfaatkan untuk kegiatan wisata bahari atau dengan kata lain pesisir Buleleng sangat layak dipergunakan sebagai kegiatan mina wisata bahari.

\section{Ikan Karang}

Berdasarkan pengamatan pada tiga stasiun menunjukkan bahwa jenis ikan karang yang ditemukan pada umumnya berupa ikan hias dengan jumlah sekitar 52 jenis. Ikan tersebut kebanyakan membentuk schooling fish (kumpulan ikan) dengan warna dan bentuk yang beranekaragam. Keanekaragaman ikan hias tersebut terdiri dari: ikan target seperti famili Acanthuridae, famili Serranidae dan famili Labridae; ikan indikator dari famili Chaetodontidae dan ikan mayor seperti famili Pomacentridae, famili Scaridae, famili Pomacanthidae, famili Aulostomidae, famili Balistidae, famili Ephipidae, famili Holocentridae, famili Nemipteridae, famili Ostraciidae, famili Pinguipedidae, famili Tetraodontidae, dan famili Zanclidae.

Keberadaan ikan di area terumbu karang sangat bergantung pada kondisi terumbu karang itu sendiri. Seperti kelompok ikan indikator (ikan Kepe-Kepe; butterfly fish; famili Chaetodontidae) yang merupakan ikan indikator untuk menilai kesehatan terumbu karang memiliki kelimpahan yang cukup banyak. Begitu pula dengan kelompok ikan mayor, seperti Chromis analis, Chromis antripectoralis, Chromis caudalis dan Chromis 
margaritifer yang cukup banyak dijumpai kehadirannya hampir di setiap stasiun pengamatan.

Masih cukup banyak dijumpainya ikan indikator, yaitu dari famili Chaetodontidae, menandakan kondisi terumbu karang masih cukup baik. Menurut (Nybakken \& Bertness, 2004) ikan indikator merupakan ikan yang aktif memangsa koloni karang, seperti ikan Kepe-Kepe (Chaetodontidae), ikan Kakak Tua (Scaridae), ikan Pakal Tato (Balistidae), dan ikan Buntal(Tretaodontidae), (Martinez \& Albenson, 2013) serta (Sammarco et al., 2014) menyebutkan bahwa kehadiran ikan Kepe-Kepe tidak terlepas dari keberadaan terumbu karang, karena ikan ini merupakan salah satu indikator kesehatan karang.

Semakin beragamnya spesies ikan dari kelompok ini menandakan tingkat kesehatan karang semakin tinggi. Keanekaragaman spesies ikan yang tinggi juga disebabkan oleh variasi habitat yang ada di ekosistem terumbu karang (Chateau \& Wantiez, 2009). Variasi habitat seperti daerah berpasir, berbagai lekuk dan celah, daerah alga, serta perairan yang dangkal atau dalam dapat menambah keragaman tidak hanya ikan tetapi juga biota laut lainnya, seperti berbagai jenis dari mega benthos.

\section{Potensi Perikanan}

Kabupaten Buleleng merupakan salah satu Kabupaten yang terletak dibagian utara Pulau Bali berbatasan dengan Laut Jawa/Bali, sehingga sebagian besar wilayah Kabupaten merupakan kawasan pesisir dengan panjang pantai 157,05 km dengan aneka ragam kekayaan laut yang potensial (luas laut 319,680 Ha). Dari penduduk yang berjumlah sebanyak 786,972 pada tahun 2009 sebanyak 4.314 orang $(0,67 \%)$ bermata pencaharian sebagai nelayan, sedangkan yang bekerja sebagai petani ikan (pembudidaya) sebanyak 864 orang $(0,13 \%)$ (BPS, 2013).

Perkembangan pembangunan dibidang perikanan dalam periode 2 tahun terakhir menunjukkan peningkatan, tercemin dari peningkatan produksi yang cukup pesat baik dalam budi daya ikan air tawar, air deras, mina padi dan kegiatan budi daya di perairan umum lainnya. Sampai dengan tahun 2012 Sub Sektor perikanan telah dapat memberikan kontribusi terhadap perkembangan PDRB Kabupaten Buleleng sebesar Rp.188.953.100.000 (BPS, 2013).

Potensi perairan Kabupaten Buleleng, selain memiliki potensi perikanan tangkap juga mempunyai potensi perikanan budi daya. Kawasan laut yang dapat dimanfaatkan sebagai budi daya mencapai luas 1000 $\mathrm{Ha}$, dengan jenis budi daya sebagai berikut : 1) budi daya Kerapu dan Bandeng yang dapat seluas $500 \mathrm{Ha}$ dan pada 2012 pemanfaatan baru mencapai 3,50 Ha $(0,70 \%)$ dengan hasil produksi sebesar 56,70 ton, dan sisa peluang investasi seluas 496,5 Ha (99,3\%) (BPS, 2013).

\section{Kualitas Perairan}

Secara umum nilai rata-rata parameter kualitas air di pesisir Buleleng masih layak atau mendukung untuk dilakukannya kegiatan mina wisata bahari. Hal ini dapat dilihat dari nilai yang didapatkan masih berada pada kisaran baku mutu air untuk wisata bahari yang ditetapkan oleh Kepmen Negara LH No. 51 Tahun 2004. Kondisi kualitas air pada perairan pesisir Buleleng dapat dilihat dalam Tabel 3.

Dari 7 parameter yang diuji (Tabel 3), tidak ada parameter yang melebihi atau melewati ambang batas baku mutu air laut untuk wisata bahari sesuai Kepmen Negara LH No. 51 Tahun 2004. Namun kondisi yang perlu mendapat perhatian adalah di stasiun II, dimana kondisi periran lebih rendah dari stasiun lainnya. Kondisi kualitas perairan stasiun II tidak terlepas dari keadaan pesisirnya yang banyak terdapat pemukiman penduduk dan letaknya yang cukup dekat dengan pantai, sehingga limbah antropogenik dapat masuk ke perairan.

Kondisi kualitas perairan pesisir Buleleng yang secara umum masih tergolong baik, sudah tentu akan berpengaruh terhadap biota dan lingkungan sekitarnya termasuk didalamnya adalah terumbu karang. Semua karang hermatipik membutuhkan cahaya yang cukup untuk kegiatan fotosintesis. Karang hermatipik adalah karang yang mampu menghasilkan terumbu.

Tabel 3.

Kondisi Kualitas Perairan Lokasi Penelitian

\begin{tabular}{llllllll}
\hline $\begin{array}{l}\text { Stasiun } \\
{ }^{\circ} \mathrm{C}\end{array}$ & $\begin{array}{l}\text { Turb } \\
(\mathrm{NTU})\end{array}$ & $\mathrm{pH}$ & $\mathrm{Sal}(\% \mathrm{0})$ & $\begin{array}{l}\mathrm{DO} \\
(\mathrm{mg} / \mathrm{l})\end{array}$ & $\begin{array}{l}\mathrm{NH}_{3}(\mathrm{mg}) \\
\mathrm{mg})\end{array}$ & $\begin{array}{l}\text { Kecepatan arus } \\
(\mathrm{cm} / \mathrm{det})\end{array}$ \\
\hline 1 & 28 & 0,055 & 7,6 & 31,4 & 7,87 & 0 & 11 \\
2 & 29 & 2,033 & 7,4 & 30,0 & 6,88 & 0 & 8 \\
3 & 28 & 0,030 & 7,8 & 31,8 & 8,05 & 0 & 10 \\
\hline
\end{tabular}


Karang hermatipik hidup bersimbiosis dengan alga (zooxanthellae) yang melakukan proses fotosintesis. Penetrasi cahaya matahari (illumination) sangat menentukan kedalaman habitat terumbu karang (Sammarco et al., 2014).

Pertumbuhan karang ditinjau dari penetrasi cahaya yang biasanya rendah diakibatkan oleh banyaknya partikel-partikel tersuspensi dari air sungai yang masuk ke laut (Harris et al., 2013). Kekeruhan dan sedimentasi yang terjadi di pesisir Buleleng masih dalam batas yang dapat ditoleransi oleh organisme karang, namun demikian sedimentasi dan kekeruhan sangat berpotensi terjadi karena dekat dengan daratan, sehingga merupakan ancaman bagi terumbu karang.

Kekeruhan air laut dan sedimentasi dapat memberikan dampak negatif terhadap pertumbuhan karang dan morfologi karang (McManus et al., 2000). Kekeruhan yang disebabkan nutrien yang kaya di perairan akan membahayakan karang dan bahkan mampu membunuh terumbu karang, salah satunya adalah akibat kompetisi antara karang dengan alga yang sudah sangat luas terjadi di sejumlah terumbu karang dengan melibatkan sejumlah interaksi. Karang yang bertahan di bawah kondisi stres berat dapat menurunkan pertumbuhan dan potensi reproduksinya (Abelson \& Yehiam, 2002).

\section{Kondisi Sosial Budaya Masyarakat Kawasan Pesisir Buleleng}

Pada dasarnya kondisi sosial budaya mayarakat lokal sangat mendukung terhadap kegiatan mina wisata bahari ini, mengingat masyarakat pesisir Buleleng sudah terbiasa dalam hal pariwisata, terlebih dengan aktivitas wisata bahari karena mina wisata bahari ini merupakan pengembangan aktivitas wisata bahari yang telah ada atau telah eksis sebelumnya seperti aktivitas diving dan snorkling.

Oleh karena itu, aktivitas mina wisata ini akan dapat diterima dan diharapkan menjadi alternatif aktivitas wisata yang telah ada sebelumnya serta menjadi jembatan antara masyarakat yang bermata pencaharian dari sektor pariwisata dengan masyarakat yang berprofesi sebagai nelayan, karena konsep mina wisata berbasiskan perikanan, sehingga ada sinergi didalam pemanfaatan sumber daya untuk mewujudkan peningkatan kesejahteraan sosial masyarakat pesisir. (Erlend et al., 2011) menyebutkan bahwa wisata perikanan dapat memberikan stimulus positif bagi masyarakat lokal dari segi ekonomi.

\section{Analisis Dampak Kegiatan Wisata Bahari Terhadap Masyarakat}

Suatu kegiatan apapun yang memanfaatkan alam atau lingkungan, pasti memiliki dampak. Untuk menganalisis dampak tersebut digunakan analisis melalui penggunan matriks IFE dan EFE. Adapun hasilnya dapat dilihat dalam Tabel 4 dan Tabel 5.

Hasil perhitungan matriks IFE, berdasarkan nilai rating maka diperoleh faktor internal yang menjadi kekuatan utama (mayor) dari masyarakat yaitu (1) potensi biofisik dengan skor nilai 0,848, (2) Dukungan dari masyarakat dengan skor nilai 0,792, dan (3) potensi tenaga kerja dengan skor nilai 0,356. Kekuatan minor dari masyarakat tidak ada. Untuk faktor internal yang menjadi kelemahan terpenting bagi masyarakat dalam pengembangan wisata bahari yaitu (1) kurangnya modal usaha dengan skor nilai 0,274.

Untuk hasil perhitungan matriks EFE, faktor eksternal yang menjadi peluang terpenting bagi masyarakat dalam pengembangan mina wisata bahari yaitu (1) diversifikasi usaha dengan skor nilai 0,568, dan

Tabel 4 . Hasil Pengolahan Matriks IFE

\begin{tabular}{lllll}
\hline & Faktor-Faktor Strategi Internal & Bobot & Rating & Skor \\
\hline & Kekuatan & & 4 & \\
1. & Potensi biofisik. & 0,212 & 4 & 0,848 \\
2. & Dukungan dari masyarakat. & 0,198 & 4 & 0,792 \\
3. & Potensi tenaga kerja. & 0,089 & & \\
\hline & Kelemahan & & 2 & 0,226 \\
1. & Keterampilan yang masih rendah. & 0,113 & 2 & 0,228 \\
2. & Pendidikan yang masih rendah. & 0,114 & 1 & 0,274 \\
3. & Kurangnya modal usaha. & 0,274 & - & 2,724 \\
\hline
\end{tabular}

Nilai rating: 1: kelemahan mayor, 2: kelemahan minor, 3: kekuatan minor, 4: kekuatan mayor 
Tabel 5 . Hasil Pengolahan Matriks EFE

\begin{tabular}{lllll}
\hline & Faktor-Faktor Strategi Eksternal & Bobot & Rating & Skor \\
\hline & Peluang & & & \\
1. & Adanya kesempatan kerja. & 0,086 & 3 & 0,258 \\
2. & Adanya kesempatan berusaha. & 0,132 & 4 & 0,528 \\
3. & Diversifikasi usaha. & 0,142 & 4 & 0,568 \\
4. & Bertambahnya wawasan dan & 0,140 & 3 & \\
& pengetahuan masyarakat. & & & 0,420 \\
\hline & Ancaman & & 3 & 0,732 \\
1. & Kerusakan sumber daya. & 0,088 & 4 & 0,288 \\
2. & Tumpang tindih kewenangan. & 0,183 & 2 & 0,170 \\
3. & Pencemaran lingkungan. & 0,144 & 2 & 3,228 \\
\hline
\end{tabular}

Nilai rating: 1 = respon masyarakat kurang, 2 = respon rata-rata, 3 = respon masyarakat bagus, $4=$ respon masyarakat sangat bagus

(2) adanya kesempatan berusaha dengan skor nilai 0,528 . Sedangkan faktor ekternal yang dapat menjadi ancaman bagi masyarakat dan dapat mempengaruhi pengembangan wisata bahari adalah tumpang tindih kewenangan dengan skor nilai 0,732.

Dilihat dari hasil perhitungan matriks IFE dan EFE tersebut, dapat diketahui bahwa masyarakat menginginkan adanya pengembangan wisata bahari di tempat tinggal mereka. Untuk itu masyarakat harus diberi kesempatan ikut serta atau dilibatkan dalam pengelolaan. Dengan melibatkan masyarakat dalam pengelolaan, selain dapat menjamin kelestarian sumber daya kelautan juga dapat menjamin kelangsungan dan kesejahteraan hidup masyarakat sekitarnya.

Melibatkan masyarakat dalam pengelolaan akan mendapatkan keuntungan ganda. Pertama mereka memperoleh pendapatan keluarga melalui pemanfaatan sumber daya untuk pariwisata, kedua mereka pasti menjaga kelestarian dan keberlangsungan dari sumber daya yang dimanfaatkan karena jika sumber daya rusak maka akan berdampak pada penurunan penghasilan mereka sehingga secara tidak langsung mereka akan menjaga keberadaan sumber daya tersebut agar tetap mendapatkan penghasilan untuk keperluan keluarga mereka.

Nikijuluw (2002), menyatakan bahwa pelibatan masyarat lokal dalam pengelolaan memberikan manfaat positif yaitu mampu mendorong pemerataan (equity) dalam pengelolaan sumber daya perikanan, mampu merefleksikan kebutuhan masyarakat lokal yang spesifik, responsif dan adaptif terhadap variasi kondisi sosial dan lingkungan lokal dan masyarakat lokal termotivasi untuk mengelola sumber daya secara berkelanjutan.

\section{Tingkat Kesesuaian Kawasan dan Rencana Model Mina Wisata Bahari}

Hasil penentuan nilai kesesuaian kawasan untuk mina wisata dilakukan dengan metode pembobotan seperti terlihat dalam Tabel 2. Kesesuaian kawasan yang dihasilkan dalam penelitian ini merupakan kesesuaian saat ini yang berdasarkan pada data yang didapatkan dan belum mempertimbangkan asumsiasumsi lainnya sehingga dapat mempengaruhi nilai kesesuaian kawasan tersebut untuk pengembangan mina wisata bahari.

Kriteria kesesuaian kawasan pengembangan mina wisata di lokasi penelitian, didapatkan dua (2) kategori, yaitu: kategori sangat sesuai (S1) dan kategori cukup sesuai (S2). Kawasan dengan kategori sangat sesuai (S1) menunjukkan bahwa sebagian besar parameter-parameter yang dikaji pada kawasan tersebut sesuai untuk pengembangan mina wisata. Tabel 6 memperlihatkan bahwa nilai parameter seperti tutupan karang hidup, jenis life form, dan jumlah jenis ikan karang yang diperoleh tergolong tinggi pada kawasan tersebut, sedangkan kawasan dengan kategori S2 beberapa parameter yang dikaji memperoleh nilai sedikit lebih rendah sehingga terkategori cukup sesuai. Namun demikian, kawasan dengan kategori S2 masih bisa mendukung dalam pengembangan mina wisata.

Kawasan dengan kategori S2, yaitu pesisir Buleleng Timur dan Tengah merupakan daerah yang mempunyai beberapa faktor pembatas dalam pengembangan mina wisata, seperti terumbu karang yang mengalami kerusakan, berada dekat dengan pemukiman padat penduduk, terdapat beberapa muara sungai, dan aktivitas lainnya sehingga diperlukan 
suatu input teknologi dan kesadaran masyarakat setempat dalam pengelolaannya. Oleh karena itu, dalam perencanaan pengembangan kawasan tersebut sebagai kawasan mina wisata diperlukan suatu upaya pengamanan agar kondisi lingkungan dapat terlindungi secara berkesinambungan. (Yulius et al., 2014) menyebutkan bahwa selain menjaga kesinambungan lingkungan diperlukan juga pertimbangan dampak negatif kegiatan wisata seperti sampah wisatawan dan perubahan budaya lokal setempat. Sedangkan (Khan et al., 2011) menyebutkan bahwa dalam pengembangan wisata bahari diperlukan juga upaya-upaya rehabilitasi dan konservasi terhadap ekosistem yang ada, dengan maksud untuk memperbaiki kondisi ekosistem yang ada agar dapat pulih kembali. Secara lengkap hasil perhitungan kesesuaian kawasan untuk mina wisata dapat disajikan dalam Tabel 6. Kondisi aktual pesisir
Buleleng yang nantinya akan dikembangkan menjadi kawasan mina wisata dapat dilihat pada Gambar 4.

Hasil perhitungan dalam Tabel 6 di atas menunjukkan bahwa secara keseluruhan kawasan pesisir Buleleng dapat dikatakan sesuai (layak) dalam menunjang kegiatan mina wisata, sedangkan rencana bentuk model mina wisata yang nantinya akan dikembangkan dapat dilihat dalam Tabel 7 .

Rencana model pengembangan mina wisata untuk kawasan pesisir Buleleng seperti dalam Tabel 7, rekomendasinya telah disesuaikan dengan kondisi potensi sumber daya alam, kondisi biofisik lingkungan dan sosial ekonomi masyarakat setempat. Kesamaan rekomendasi hanya terletak pada rencana aktivitas mina wisata perikanan tangkap. Hal ini dikarenakan,

Tabel 6.

Matriks Hasil Kesesuaian Kawasan Untuk Mina Wisata

\begin{tabular}{|c|c|c|c|c|}
\hline No & Parameter & $\begin{array}{c}\text { I } \\
\text { (Pesisir Buleleng Timur) }\end{array}$ & $\begin{array}{c}\text { Stasiun } \\
\text { II } \\
\text { (Pesisir Buleleng Tengah) }\end{array}$ & $\begin{array}{c}\text { III } \\
\text { (Pesisir Buleleng Barat) }\end{array}$ \\
\hline \multirow[t]{2}{*}{1} & Karang hidup (\%) & $>50-75$ & $25-50$ & $>75$ \\
\hline & Nilai & 6 & 3 & 9 \\
\hline \multirow[t]{2}{*}{2} & Kecerahan perairan (\%) & $80-<100$ & $80-<100$ & $80-<100$ \\
\hline & Nilai & 6 & 6 & 6 \\
\hline \multirow[t]{2}{*}{3} & Jumlah jenis life form & $>12$ & $<7-12$ & $>12$ \\
\hline & Nilai & 6 & 4 & 6 \\
\hline \multirow[t]{2}{*}{4} & Jumlah jenis ikan karang & $>100$ & $50-100$ & $>100$ \\
\hline & Nilai & 6 & 4 & 6 \\
\hline \multirow[t]{2}{*}{5} & Kedalaman terumbu karang $(\mathrm{m})$ & $>15-20$ atau $3-5$ & $>15-20$ atau $3-5$ & $>15-20$ atau $3-5$ \\
\hline & Nilai & 4 & 4 & 4 \\
\hline \multirow[t]{4}{*}{6} & Kecepatan arus (cm/det) & $>15-30$ & $0-15$ & $0-15$ \\
\hline & Nilai & 2 & 3 & 3 \\
\hline & Total Nilai & 76,92 & 61,53 & 87,17 \\
\hline & Kategori & S2 (cukup sesuai) & S2 (cukup sesuai) & S1 (sangat sesuai) \\
\hline
\end{tabular}

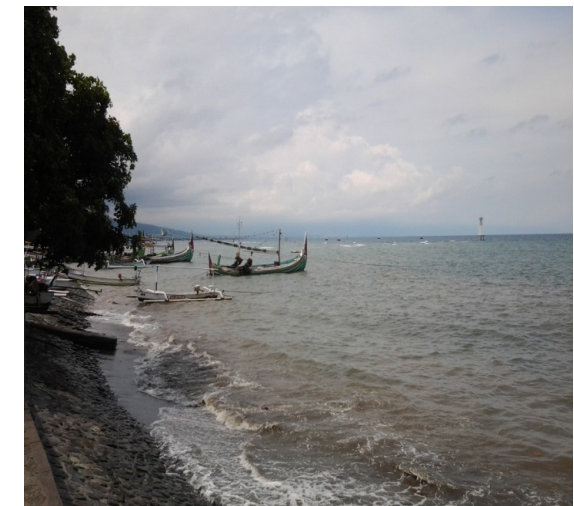

(a)

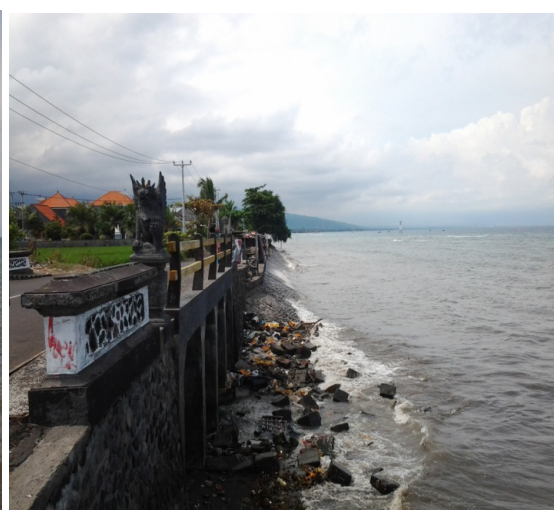

(b)

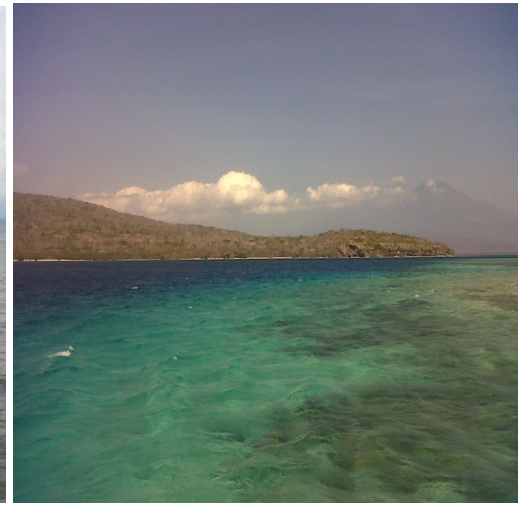

(c)

Gambar 4. Kondisi Pesisir Buleleng (a) Timur, (b) Tengah dan (c) Barat. 
Tabel 7.

Rencana Model Pengembangan Mina Wisata

\begin{tabular}{lll}
\hline No & Wilayah & Aktivitas \\
\hline 1 & Pesisir Buleleng Timur & $\begin{array}{l}\text { 1. Mina wisata budi daya (ikan hias dan karang) } \\
\text { 2. Mina wisata perikanan tangkap (mancing, spearfishing adventures) }\end{array}$ \\
3 & Pesisir Buleleng Tengah & $\begin{array}{l}\text { 1. Mina wisata budi daya (rumput laut) } \\
\text { 2. Mina wisata perikanan tangkap (mancing, spearfishing adventures) }\end{array}$ \\
& Pesisir Buleleng Barat & $\begin{array}{l}\text { 1. Mina wisata budi daya (rumput laut, Bandeng, Kerapu, Mutiara, ikan hias, karang) } \\
\text { 2. Mina wisata perikanan tangkap (mancing, spearfishing adventures) }\end{array}$
\end{tabular}

persyaratan pengembangan atraksinya lebih mudah diimplementasikan dan memerlukan biaya investasi yang tidak terlalu besar serta lebih mudah diterima secara sosial oleh masyarakat setempat.

Adanya perbedaan corak aktivitas mina wisata perikanan budi daya di setiap kawasan kajian, juga karena ada pertimbangan penetapan beberapa desa pesisir di Buleleng sebagai sentra produksi perikanan budi daya oleh Dinas Kelautan dan Perikanan setempat, sehingga terdapat ciri khas di masing-masing wilayah. Namun demikian tidak menutup kemungkinan corak aktivitas dapat ditambah apabila telah ada kajian ilmiah untuk hal tersebut.

\section{KESIMPULAN}

Dari hasil dan pembahasan yang diperoleh maka dapat disimpulkan bahwa pesisir Kabupaten Buleleng apabila dilihat dari kondisi dan potensi sumber daya alamnya masih mampu untuk mendukung aktivitas mina wisata dengan tingkat kesesuaian kawasan berdasarkan indeks kesesuaian wisata, yaitu pesisir Buleleng timur terkategori cukup sesuai $(76,92)$, pesisir Buleleng tengah terkategori cukup sesuai $(61,53)$ dan pesisir Buleleng barat terkategori sangat sesuai $(87,17)$. Rencana model mina wisata yang dapat dikembangkan antara lain pesisir Buleleng timur adalah mina wisata budi daya (ikan hias dan karang) dan mina wisata perikanan tangkap (mancing dan spearfishing adventures), pesisir Buleleng tengah adalah mina wisata budi daya (rumput laut) dan mina wisata perikanan tangkap (mancing dan spearfishing adventures), dan pesisir Buleleng barat adalah mina wisata budi daya (rumput laut, Bandeng, Kerapu, Mutiara, ikan hias dan karang) dan mina wisata perikanan tangkap (mancing dan spearfishing adventures).

\section{PERSANTUNAN}

Penulis menyampaikan ucapan terima kasih kepada pihak DP2M Dikti atas kepercayaan yang diberikan kepada penulis untuk mengerjakan penelitian dengan SPK nomor: 54/UN48.14/PL/2014 Tanggal 6 Maret 2014.

\section{DAFTAR PUSTAKA}

Abelson, A. \& Yehiam, S. (2002). Comparison of The Development of Coral and Fish Communities on Rock Aggregated Artificial Reefs In Eilat Red Sea. ICES Journal of Marine Science, 59:122-126.

Bakorsurtanal. (2001). Peta Potensi Sumber daya Alam wilayah Pesisir dan Laut Kabupaten Buleleng Provinsi Bali, 143 hal.

BPS. (2013). Buleleng Dalam Angka. Badan Pusat Statistik Kabupaten Buleleng. Bali, 205 hal.

Bachtiar. (2001). Pengelolaan Terumbu Karang. Pusat Kajian Kelautan Universitas Mataram. NTB, 74 hal.

Chateau, O. \& Wantiez, L. (2009). Movement Patterns of Four Coral Reef Fish Species in A Fragmented Habitat In New Caledonia: Implications For The Design of Marine Protected Area Networks. ICES Journal of Marine Science, 66 (1): 50-55.

Darmawan, A. \& Miftahul, A. (2012). Pengembangan Minawisata Pulau-Pulau Kecil Untuk Mendukung Implementasi Blue Economy. KONAS VIII Pengelolaan Pesisir, Laut dan Pulau-Pulau Kecil. Mataram.

Davenport, J. \& Davenport, J.R. (2006). The Impact of Tourism and Personal Leisure Transport on 
Coastal Environments: A review. Estuarine, Coastal and Shelf Science, 67(1-2): 280-292.

deVantier, L. \& Turak, E. (2004). Managing Marine Tourism in Bunaken National Park and Adjacent Waters. Technical Report was prepared by The Natural Resources Management (NRM III) Program's Protected Areas and Agriculture Team. Manado.

Dexter, W., Ronald, D. \& Maria, V. (2014). Community Based, Low-Tech Method of Restoring A Lost Thicket of Acropora Corals. ICES Journal of Marine Science, 71 (7): 1866-1875.

English, S., Wilkinson, C. \& Baker, V. (1994). Survey Manual for Tropical Marine Resource. Australian Institute of Marine Science. Townsville.

Erlend, M., Jakob, G., Guillaume, L., Eirik, M., Esben, M., Hakan, T. \& Volstad, J. (2011). Effects of Fishing Tourism in a Coastal Municipality: a Case Study from Risor Norway. Ecology and Society, 16(3):11-21.

Davis, D. \& Tisdell, C. (1995). Recreational SCUBA Diving and Carrying Capacity in Marine Protected Areas. Ocean and Coastal Management, 26:1940.

Davis, D. \& Tisdell, C. (1996). Economic Management of Recreational SCUBADiving and The Environment. Journal of Environmental Management, 48: 229 248.

Ferter, K., Weltersbach, M, S., Strehlow, H, V., Volstad, J, H., Alo's, J., Arlinghaus, R., Armstrong, M., Dorow, M., de Graaf, M., van der Hammen, T., Hyder, K., Levrel, H., Paulrud, A., Radtke, K., Rocklin, D., Sparrevohn, C. R. \& Veiga, P. (2013). Unexpectedly High Catch-And-Release Rates In European Marine Recreational Fisheries: Implications for Science and Management. ICES Journal of Marine Science, 70:1319 - 1329.

Harris, P, T., Bridge, T., Beaman, R., Webster, J., Nichol, S. \& Brooke, B. (2013). Submerged Banks in The Great Barrier Reef, Australia, Greatly Increase Available Coral Reef Habitat. ICES Journal of Marine Science, 70 (2):284-293.

Hutabarat, A., Yulianda, F., Fahrudin, A., Harteti, S. \& Kusharjani. (2009). Pengelolaan Pesisir dan Laut Secara Terpadu (Edisi I). Pusdiklat Kehutanan. Deptan. SECEN-KOREA International Coorperation Agency.

Kasnir, M. (2011). Analisis Aspek Ekologi
Penatakelolaan Minawisata Bahari di Kepulauan Spermonde Kabupaten Pangkep Sulawesi Selatan. Jurnal IImu Kelautan, 16(2):61- 69.

Khan, A.M.A., Sondita, F.A. \& Iskandar, B.H. (2011). Studi Potensi Ekowisata Bahari Di Kabupaten Batubara (Studi Kasus Pada Pulau Pandang). Jurnal Segara, 7(1): 17-28.

Martinez, S. \& Abelson, A. (2013). Coral Recruitment: The Critical Role of Early Post-Settlement Survival. ICES Journal of Marine Science, 70 (7): 1294-1298.

McManus, J., Menez, L., Kesner-Reyes, L.,Vergara, S. \& Ablan, M. (2000). Coral Reef Fishing and Coral-Algal Phase Shifts: Implications for Global Reef Status. ICES Journal of Marine Science, 57 (3):572-578.

Nybakken, J.W. \& Bertness, M. (2004). Marine Biology. An Ecological Approach. Six Edition. Benjamin Cummings Publishers. New York. 592p.

Nikijuluw, V. (2002). Rezim Pengelolaan Sumberdaya Perikanan. PT. Pustaka Cidesindo. Jakarta.

Sammarco, P, W., Lirette, A., Tung, Y, F., Boland, G, S., Genazzio, M. \& Sinclair, J. (2014). Coral Communities on Artificial Reefs In The Gulf of Mexico: Standing vs Toppled Oil Platforms. ICES Journal of Marine Science, 71 (2): 417- 426.

Simon, F., Yeamduan, N. \& Daniel, P. (2004). Carrying Capacity in The Tourism Industry: A Case Study of Hengistbury Head. Tourism Management Journal, 25:275-283.

Strehlow, H, V., Schultz, N., Zimmermann, C. \& Hammer, C. (2012). Cod Catches Taken by The German Recreational Fishery In The Western Baltic Sea, 2005-2010: implications For Stock Assessment And Management. ICES Journal of Marine Science, 69:1769 -1780.

Stone, R, P., Michele, M \& John F, K. (2015). Assessing The Ecological Importance of Red Tree Coral Thickets In The Eastern Gulf of Alaska. ICES Journal of Marine Science, 72 (3): 900-915.

Tratalos, J. \& Austin, T. (2001). Impacts of Recreational SCUBA Diving on Coral Communities of The Caribbean island of Grand Cayman. Biological Conservation, 102 (1): 67-75.

Volstad, J, H., Korsbrekke, K., Nedreaas, K, H., Nilsen, M., Nilsson, G, N., Pennington, M., Subbey, S. \& Wienerroither, R. (2011). Probability-Based 
Surveying Using Self-Sampling To Estimate

Catch and Effort In Norway's Coastal Tourist

Fishery. ICES Journal of Marine Science, 68: 1785-1791.

Yudasmara, A, G. (2010). Model Ekowisata Bahari Di Pulau Menjangan Kawasan Taman Nasional Bali Barat. Disertasi. Institut Pertanian Bogor. Bogor.

Yulius., Salim, H, L., Ramdhan, M., Arifin, T. \& Purbani, D. (2014). Penentuan Kawasan Wisata Bahari Di P.Wangi-Wangi dengan Sistem Informasi Geografis. Jurnal Segara, 10(2): 157-164.

Zakai, D. \& Chadwick, N. (2002). Impacts of Intensive Recreational Diving on Reef Corals at Eilat, Northern Red Sea. Biological Conservation, 105 (2): $179-187$. 
